\section{KURZ GEMELDET}

Allergy News

\section{Schützt Helicobacter vor}

st die Zunahme an Asthmaerkran-

kungen möglicherweise auf das gezielte

Ausmerzen von Helicobacter pylori in der westlichen Welt zurückzuführen? Hinweise darauf geben jetzt Ergebnisse einer tierexperimentellen Studie aus Zürich und Mainz: Die Forscher hatten Mäuse kurz nach der Geburt mit Ovalbumin sensibilisiert und mit dem Magenbakterium infiziert. Bei der Methacholin-Provokation zeigte sich im Vergleich zu nicht infizierten Tieren eine signifikant geringere Atemwegshyperreagibilität. Wurde jedoch der Keim mit Hilfe von Antibio-

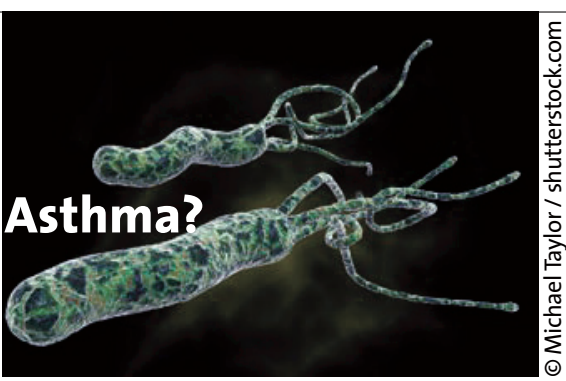

tika eradiziert, verschwand dieser Asthmaschutz wieder. Der protektive Effekt war auch auf zellulärer Ebene nachweisbar: In der bronchoalveolären Lavage zeigten sich bei mit Helicobacter pylori infizierten Mäusen weniger reife dendritische Zellen und eine Akkumulation von regulatorischen T-Zellen.

es

Arnold IC et al. J Clin Invest 2011; 121: 3088-93

\title{
Der feine Unterschied beim H1-Rezeptor
}

S chon kleine Unterschiede in der Molekülstruktur eines Rezeptors können zu einer deutlich anderen Selektivität führen. Zu diesem Schluss kamen japanische Wissenschaftler als sie die Kristallstruktur eines Komplexes des Histamin-H1-Rezeptors (H1R) mit Doxepin, einem H1RAntagonisten der ersten Generation, studierten. Das Doxepin sitzt bei diesem Komplex in der Liganden-Bindungstasche und wechselwirkt direkt mit Tryptophan $428^{6.48}$, einem hoch konservierten Schlüsselrest der G-Protein-gekoppelten Rezeptoraktivierung. Diese Tasche spielt bei der geringen Selektivität von Verbindungen der ersten Generation eine Rolle. Bindungsmodelle mit verschiedenen H1RAntagonisten der zweiten Generation offenbaren, dass die einzelne CarboxylGruppe, die in dieser Verbindungsklasse vorkommt, mit Lys $191^{5.39}$ und/oder Lys $179^{\text {ECL2 }}$ interagiert - beide sind Teil einer Anion-Bindungs-Region, die mit der erwähnten Bindungstasche assoziiert ist. In anderen aminergen Rezeptoren fehlt diese Region.

Marion Weber

Shimamura T et al. Nature 2011; 475: 65-70

\section{Stress weg - Ekzem weg}

tress meiden und Sport treiben - diese einfache Formel scheint vor Handekzemen zu schützen und ist das Ergebnis einer Befragung von knapp 27.800 Bewohnern des Großraums Stockholm. Insgesamt war bei knapp $8 \%$ der Teilnehmer innerhalb eines Jahres ein Handekzem aufgetreten. Bei gestressten Personen war dies um knapp $33 \%$ häufiger der Fall gewesen als bei ausgeglichenen Zeitgenossen. Auch eine Adipositas ging mit einer um $20 \%$ erhöhten Prävalenz

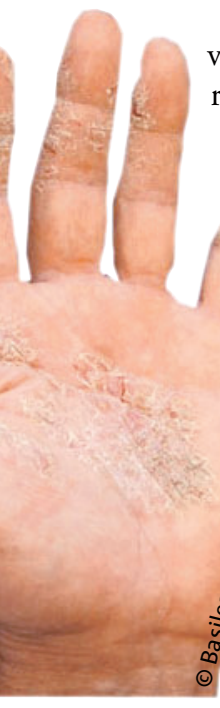

von Handekzemen einher. Überraschend war jedoch, dass sportlich Aktive deutlich seltener über Handekzeme berichteten als CouchPotatoes. Als Erklärung für ihre Beobachtungen vermuten die Studienautoren, dass bei Bewegung die Plasmawerte von antiinflammatorischen Zytokinen ansteigen, während Stress proinflammatorisch wirkt. Thomas Müller

Anveden Berglind I et al. $\mathrm{Br}$ J Dermatol 2011; 165: 568-75

\section{Schon Babys reagieren}

ontaktallergien bei Babys und Kleinkindern gelten als Seltenheit, nicht zuletzt weil die Dauer der Exposition für eine Sensibilisierung als zu kurz erscheint. Da erstaunt das Ergebnis einer Studie aus Italien, in der sich bei 200 von 321 Kindern $(62,3 \%)$ unter drei Jahren, die an einer immer wiederkehrenden Dermatitis litten, eine Kontaktallergie im Patch-Test nachweisen ließ. Die Hitliste der Auslöser führte Nickelsulfat mit $26,8 \%$ an, es folgten Kaliumbichromat, Cocamidopropyl-Betaine, Kobaltchlorid, Neomycinsulfat, Methylisothiazolinon und Dispersionsfarbstoffe. Offenbar sind die Kinder mit diesen Allergenen schon von Geburt an konfrontiert: So findet sich Nickel z. B. in Druckknöpfen, einige der anderen Substanzen sind in Pflegeprodukten für Babys enthalten. Ein Zusammenhang mit einer atopischen Dermatitis bestand nicht: Die Prävalenz einer Kontaktallergie war bei Kindern mit $(61,3 \%)$ und ohne Ekzem (63\%) gleich hoch. Dr. Dagmar Kraus

Fortina A et al. J Am Acad Dermatol 2011; $65: 772-9$

\section{Garantiert allergenfrei}

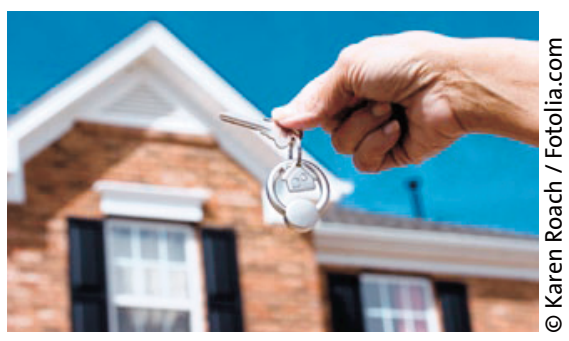

_ in Tipp für die Bauherren unter Ihren — Patienten: Sie können bei der Beauftragung eines Schlüsselfertighauses vertraglich fixieren, dass für sie relevante Allergene nicht verwendet werden. Dazu muss eine Liste der bekannten Sensibilisierungen der Familienmitglieder vorliegen. Die Liste wird mit dem Generalunternehmer besprochen und im Bauvertrag festgeschrieben. Im Idealfall verpflichtet sich dieser sogar, alle verbauten Stoffe für den Bauherren zu dokumentieren.

es

Verband Privater Bauherren (www.vpb.de) 